Original article

https://www.journal-imab-bg.org

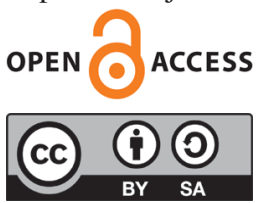

\title{
KINESIOTAPE METHODOLOGY FOR CHRONIC PAIN SYNDROME IN THE LUMBOSACRAL REGION
}

\author{
Stamenka Mitova, Mariya Gramatikova, Margarita Avramova, Georgi Stoyanov \\ Department of Kinesitherapy, Faculty of Public Health, Healthcare and Sports, \\ South-West University NeofitRilski, Blagoevgrad, Bulgaria.
}

\section{SUMMARY}

Purpose: The study aims to evaluate the effect of kinesiotape methodology on chronic pain syndrome in the lumbosacral region.

Material and Methods: 42 participants with chronic low back pain were recruited and randomly divided into two groups - control $(n=19)$ and experimental $(n=23)$. Foreword and lateral tilt, Borg and Modified Merld'Aubigne Scale for pain were used for assessment before and after treatment. Roland-Morris Questionnaire was done to assess the quality of life before and three months after treatment. The participants received a specialized kinesitherapy program combined with kinesio tape daily for 15 days with a duration of 40 minutes per procedure. They all received a home kinesitherapy program. Data were analyzed using GraphPad prism 3.02.

Results: 42 participants, including 20 women and 22 men, were examined. The mean age $(\bar{X} \pm \mathrm{SD})$ of the control group was $45 \pm 9.08$ years, and for experimental was49.13 \pm 8.3 years. Median values of the Borg pain scale were as follows: $7.53 \pm 0.84$ before, and $6.05 \pm 0.78$ after treatment for the control group and 7.39 \pm 0.99 and $4.61 \pm 0.78$ for the experimental group. Merld'AubigneScaleshows before and after treatment for control group 4.26 \pm 065 and $3.12 \pm 0.49$ respectively, while in experimental was $4.26 \pm 0.68$ and $2.09 \pm 0.44$ after treatment. The average of forwarding tilts measured before and after treatment was $13.79 \pm 3.77 \mathrm{~cm}$ and $10 \pm 3.6 \mathrm{~cm}$ for the control group and $13.13 \pm 3.76$ and $7.52 \pm 2.25$ for the experimental group. Initially, the quality of life questionnaire shows 17.26 \pm 1.66 and three months later was $12 \pm 1.45$ for the control group and $17.35 \pm 1.5$ before, and descend to $9.00 \pm 1.04$ for the experimental group. There were statistically significant differences before and after treatment $(\mathrm{p}<0.05)$.

Conclusions: Treatment significantly reduces pain and muscle spasms after application and improves thefunctionality of the lumbar spine. Kinesiotape not only helps the reduction of pain symptoms in musculoskeletal pathologies but is also a valuable addition to the kinesitherapy procedures.

Keywords: kinesiotape, kinesitherapy, low back, pain, dysfunction,

\section{INTRODUCTION}

Kinesio Taping has been widely used in clinical practice [1]. Low back pain is a serious worldwide health problem [2] and has been quoted as the major cause of disability around the world [3].

It is estimated that globally $39 \%$ of the population will have at least one episode of back pain throughout their lives. In episodes of pain greater than 12 weeks (classified as chronic lower back pain), the prognosis is unfavorable and is highly associated with high treatment costs and work absenteeism [4].

Chronic low back pain is a common condition. A new intervention that is popular in sports has been used in patients with low back pain. This technique is based on the use of elastic tapes that are fixed on the skin of patients using different tensions and is namedthe Kinesio Taping Method. Although this intervention has been widely used to date, evidence of its effectiveness is lacking [5].

Management of chronic low back pain currently comprises a range of intervention strategies, including physical treatments (e.g. electrotherapy, traction), exercise therapy, manual therapy (mobilization/manipulation and massage), drug therapy (e.g. paracetamol, non-steroidal anti-inflammatory drugs (NSAIDs), opioids, muscle relaxants) and invasive procedures (e.g. acupuncture, injections and nerve blocks). In most situations, the therapeutic effect of a single therapy is not significant, and a combination of the above methods is recommended to achieve a good curative effect [4]

Kinesio taping is the application of an elastic tape, which can be stretched up to $140 \%$ of its original length (approximately the stretch capability of normal skin) for treating musculature-related conditions [6]. Kinesio taping attached to injured skin or muscle regions may enhance muscle strength, relieve spasms, pain and oedema, improve blood circulation and lymph reflux, as well as stabilize joints and increase range of motion. Kinesiotape, as a rehabilitative taping technique designed to promote the body's natural healing process, is widely applied in the treatment of chronic non-specific low back pain [4].

This study aims to evaluate the effect of Kinesiotape methodology on chronic pain syndrome in the lumbosacral region. 


\section{MATERIAL AND METHODS}

The study includes 42 patients (20 females and 22 males) randomly divides into two groups. All participants see the inclusion criteria-mean age $( \pm$ SD) for the control group $45 \pm 9.08$ years and $49.13 \pm 8.3$ years for the experimental group.

Functional tests and physiotherapy procedures were conducted after informed written consent. The study methodology includes conducting functional tests - an anamnesis, somatoscopy (view), Range of movement by forward and lateral tilts, Borg and Merld'Áubigne Scales for pain and Rolan-Morris Questionnaire for quality of life.

Foreword and lateral tilt were done to assess the mobility of the lumbar region of the spine. Patients were pleased to do foreword or left, and right tilt and the toefloor distance were measured from the top of the third finger to the floor $(\mathrm{cm})$.

Borg and Modified Merld'Aubigne Scale for pain were used for assessment of pain before and after treatment.

To assess the static pain, we used Borg Scale. The intensity of the pain is determined in 12 degrees with the numbers from 0 to 10 , where at 0 - there is no pain, and at degree 10, the pain is maximum. This scale registers the subjective perception of patients of static back pain, as well as the strength of its irradiation.

For examination of dynamic pain, we used Modified Merld'Aubigne Scale. This is a subjective scale, which was used to assess dynamic pain - pain when moving [7]. The strength of pain is determined in 6 degrees with the numbers from 0 to 5 , where at 0 - no pain, free movement, and in grade 5 , there is severe pain at the beginning of the movement, blocking it, a weak effect of analgesics.

Roland-Morris Questionnaire was done to assess the quality of life before and three months after treatment.

The participants received a specialized kinesitherapy program combined with Kinesiotape daily for 15 days with a duration of 40 minutes per procedure. The specialized kinesitherapeutic program includes exercises for the abdominal and gluteal muscles, relaxation techniques for $\mathrm{m}$. Iliopsoas and $\mathrm{m}$. Erector Spinaelumbalis, manual therapyand Kinesiotape applications.

Before applying the tape, a Screening test is applied to detect the problem. Kinesiotapeis placed at maximum tension of the muscle.

Tension of Kinesio Tech tape.

$0-10 \%$ - when exposed to myofascia

$10-15 \%$ - inhibition of myofascia

$15-25 \%$ - facilitation of myofascia

$25-35 \%$ - corrective techniques

$50-75 \%$ - tendon, ligament, mechanical corrections

$75-100 \%$ - for mechanical corrections and liga-

ment techniques

$0 \%$ - on the edges of the application, which should be about $5 \mathrm{~cm}$ long each. In general, the applications have an optimal effect of up to 3-4 days, but when the tension is high, $75 \%-100 \%, 12-24$ hours are enough for athletes 3-4 hours. It is applied: D to P (Distal '! Proximal) - For inhibition in sharp and overloaded muscles. It is applied from distal to proximal with a tape tension of $15 \%-25 \%$ - P to D (Proximal '! Distal). To facilitate the work of weak muscle, in chronic conditions, rehabilitation $15 \%-35 \%$ tension [11].

All patients received a home kinesitherapy program which includes a specialized exercise program for straightening of the weak muscle groups and stretching exercises and relaxation techniques for the shortened and tensed muscle groups.

Data were analyzed using GraphPad prism 3.02.

\section{RESULTS}

Forty-two people, including 20 women and 22 men, were recruited. The mean age of the observed contingent $(\mathrm{X} \pm \mathrm{SD})$ for the control group was $45 \pm 9.08$ years and for the experimental was $49.13 \pm 8.3$ years, mean values of height and weight are as follows for control group $173.6 \pm 3.59 \mathrm{~cm}$ and $73.68 \pm 7.8$, and for the experimental $170.3 \pm 4.2 \mathrm{~cm}$ and $70 \pm 7.03 \mathrm{~kg}$. The primary characteristics are represented in Table 1.

Table 1. Primary characteristics of experimental and the control group

\begin{tabular}{|l|c|c|c|c|}
\hline Groups & $\boldsymbol{N}$ & $\begin{array}{c}\text { Mean age (years) } \\
(\boldsymbol{X} \pm \boldsymbol{S D})\end{array}$ & $\begin{array}{c}\text { Mean weight }(\mathrm{kg}) \\
(\boldsymbol{X} \pm \boldsymbol{S D})\end{array}$ & $\begin{array}{c}\text { Mean height }(\mathrm{cm}) \\
(\boldsymbol{X} \pm \boldsymbol{S D})\end{array}$ \\
\hline Experimental group $(\mathrm{EG})$ & $(\mathbf{N}=\mathbf{2 3})$ & $49.13 \pm 8.3$ & $170.3 \pm 4.2$ & $70 \pm 7.03$ \\
\hline Control group $(\boldsymbol{C G})$ & $(\mathrm{N}=19)$ & $45 \pm 9.08$ & $173.6 \pm 3.59$ & $73.68 \pm 7.8$ \\
\hline
\end{tabular}

Median values of the Borg pain scale were as follows: $7.53 \pm 0.84$ before and $6.05 \pm 0.78$ after treatment for the control group and $7.39 \pm 0.99$ and $4.61 \pm 0.78$ for the experimental group (fig. 1A).

Merld'AubigneScale shows before and after treatment for control group $4.26 \pm 065$ and $3.12 \pm 0.49$ respectively, while in experimental was $4.26 \pm 0.68$ and $2.09 \pm 0.44$ after treatment (fig. 1B). 
Fig. 1. Results of Borg Scale (A) and Merld'Aubigne Scale (B) before and after kinesitherapy for control and experimental group $(* * * \mathrm{p}<0.05$, Mann Withney)

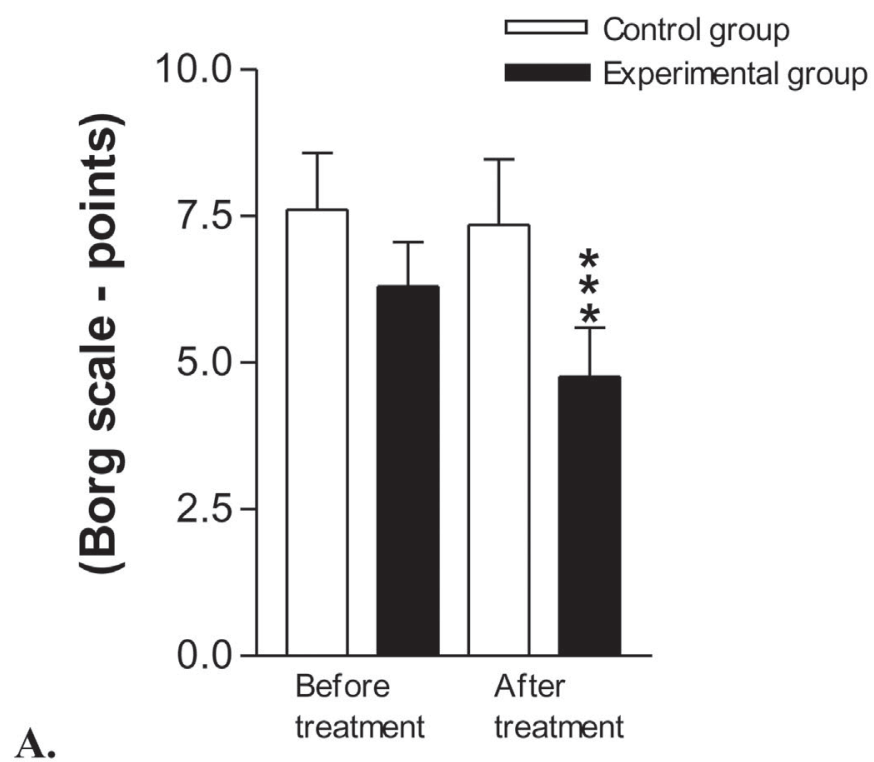

The average of forwarding tilts measured before and after treatment was $13.79 \pm 3.77 \mathrm{~cm}$ and $10 \pm 3.6 \mathrm{~cm}$ for the control group and $13.13 \pm 3.76 \mathrm{~cm}$ and $7.52 \pm 2.25 \mathrm{~cm}$ for the experimental group (Figure 2 A.). Initially, the quality of life questionnaire shows $17.26 \pm 1.66$ and three months later was

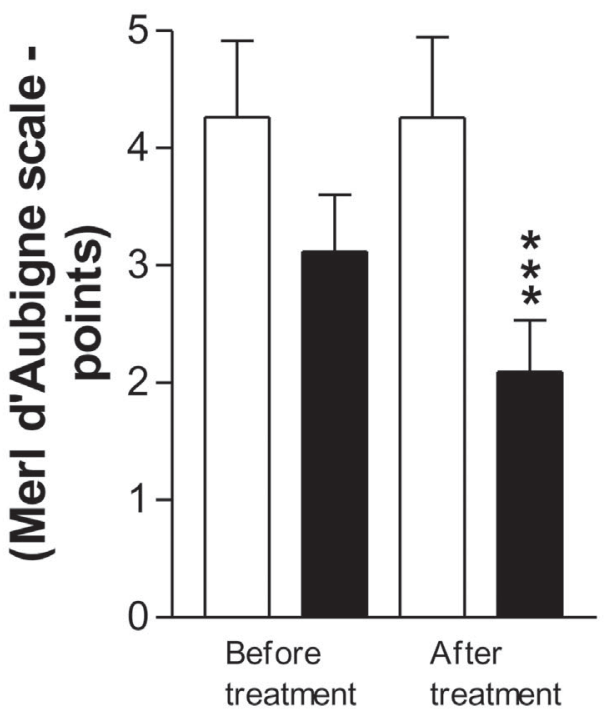

Fig. 2. Results of Forwarding tilts (A) and Roland-Morris Questionnaire (B) before and after kinesitherapy for control and experimental group $(* * * \mathrm{p}<0.05$, Mann Whitney)

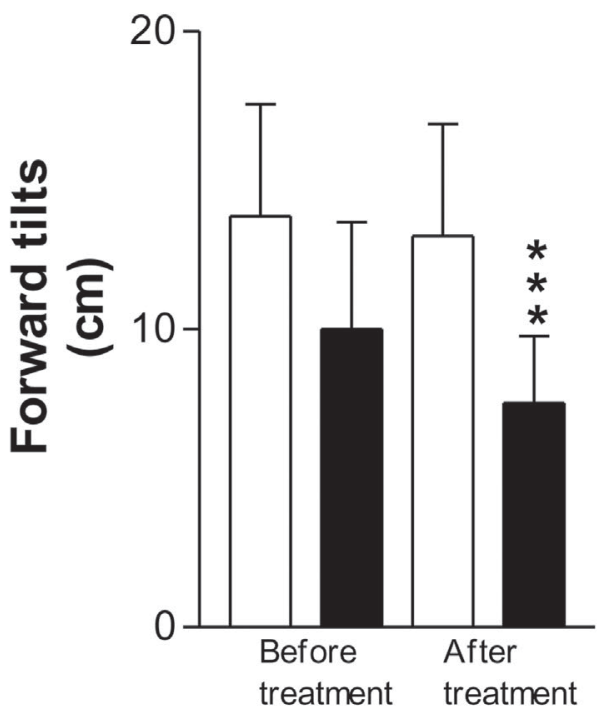

$12 \pm 1.45$ for the control group and $17.35 \pm 1.5$ before, and descend to $9.00 \pm 1.04$ for the experimental group. (Figure 2B)There were statistically significant differences before and after treatment $(\mathrm{p}<0.05)$.

\section{DISCUSSION}

The study aims to evaluate the effect of kinesiotape methodology on chronic pain syndrome in the lumbosacral region. The obtained results show that the application of Kinesio taping is an effective method to relieve pain, improve range of movement and, as a consequence the improve the quality of life of the patients.

A.

B.

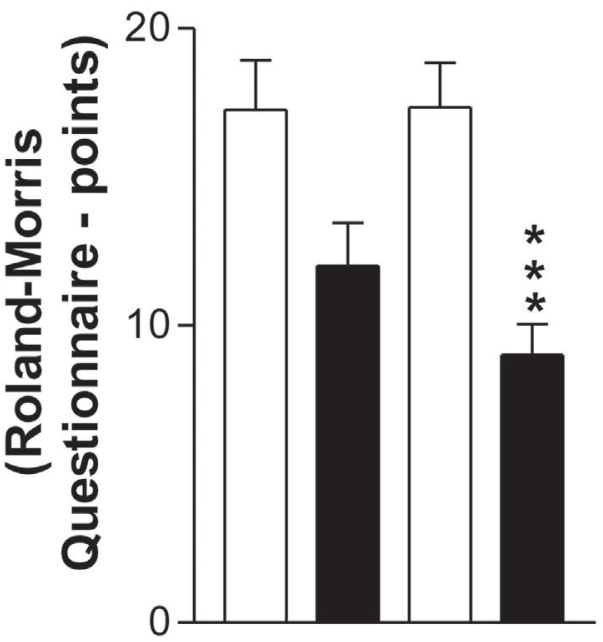

The results obtained in our study show a strong reduction in pain. This is particularly important as it is one of the main limiting factors and leads to a decrease in the volume of movement and functionality in the lumbar spine [8]. A number of other studies have reported a positive effect on pain symptoms after manual therapy $[9,10]$.

In addition to manual therapy, the applied special- 
ized kinesitherapy complex additionally builds a strong muscular corset that keeps the lumbar region in the correct position.

The exercises are aimed at strengthening the weak muscle groups - abdominal and buttock muscles, related to building an incorrect position in the lumbar region, and accordingly relax their antagonists, with proven increased muscle tone, namely muscles in the lumbar region and flexors of the hip joints. Special emphasis is placed on the relaxation technique of $\mathrm{m}$. iliopsoas, which is associated with a number of pathologies in the lumbar region when it is in increased tone.

In turn, kinesiotape applications also have a proven strong analgesic and anti-inflammatory effect in the area where they are applied [11]. This is also demonstrated in the present study, with the majority of patients reporting pain reduction from the first application of kinesiotape.

In addition to this momentary effect, kinesiotape applications significantly improve the range of movement and help to retain the result of each procedure, which leads to the retention of positive results for a longer period of time. This was one of the main goals of the present study, namely to retain and track the results obtained for as long as possible.
In a study by Evans et al. from 2018, it has been reported that a combined method of manual therapy and kinesitherapy exercises leads to significantly better results in lower back pain in a growing group of patients aged 12-18 years [12]. In our study, we demonstrated the same positive effect in middle-aged patients with the same diagnosis.

In summary of a number of studies comparing kinesiotape applications with a routine kinesitherapy program, it has been reported that kinesiotape applications could not replace physical therapy, exercise, and kinesitherapy procedures. Kinesio taping in itself has a momentary positive effect, but if not applied in combination with manual therapy and a specialized set of exercises, this effect cannot be maintained for a longer period of time and is not particularly significant $[13,14]$.

\section{CONCLUSION}

Treatment significantly reduces pain and muscle spasms after application and improves the functionality of the lumbar spine. Kinesiotape not only helps the reduction of pain symptoms in musculoskeletal pathologies but is also a valuable addition to the kinesitherapy procedures.

\section{REFERENCES:}

1. Luz Júnior MA, Sousa MV, Neves LA, Cezar AA, Costa LO. Kinesio Taping ${ }^{\circledR}$ is not better than placebo in reducing pain and disability in patients with chronic non-specific low back pain: a randomized controlled trial. Braz J Phys Ther. 2015 Nov-Dec;19(6):482-90. [PubMed]

2. Da C Menezes Costa L, Maher CG, Hancock MJ, McAuley JH, Herbert RD, Costa LO. The prognosis of acute and persistent low-back pain: a meta-analysis.CMAJ. 2012 Aug 7;184(11):E613-24. [PubMed]

3. Hoy D, March L, Brooks P, Woolf A, Blyth F, Vos T, et al. Measuring the global burden of low back pain.Best Pract Res Clin Rheumatol. 2010 Apr;24(2):155-65. [PubMed]

4. Sheng Y, Duan Z, Qu Q, Chen W, $\mathrm{Yu}$ B. Kinesio taping in treatment of chronic non-specific low back pain: a systematic review and metaanalysis.J Rehabil Med. 2019 Oct 29;51(10):734-740. [PubMed]

5. Silva Parreira Pdo C, Menezes Costa Lda C, Takahashi R, Hespanhol Junior LC, Motta Silva T, da Luz Junior MA, et al. Do convolutions in
Kinesio Taping matter? Comparison of two Kinesio Taping approaches in patients with chronic non-specific low back pain: protocol of a randomized trial. J Physiother. 2013 Mar;59(1):52. [PubMed]

6. Paoloni M, Bernetti A, Fratocchi G, Mangone M, Parrinello L, Del Pilar Cooper M, et al. Kinesio Taping applied to lumbar muscles influences clinical and electromyographic characteristics in chronic low back pain patients. Eur J Phys Rehabil Med. 2011 Jun;47(2):237-44. [PubMed]

7. Ugino FK, Righetti CM, LedioAlves DP, Guimaraes RP, Honda EK, Ono NK. Evaluation of the realibility of the modified merle d'Aubigne and Postel Method. Acta Ortop Bras 2012; 20(4):213-7. [PubMed]

8. Zhao L, Chen J, Li Y, Sun X, Chang X, Zheng H, et al. The Longterm Effect of Acupuncture for Migraine Prophylaxis: A Randomized Clinical Trial. JAMA Intern Med. 2017 Apr 1;177(4):508-515. [PubMed]

9. Hershman DL, Unger JM, Greenlee H, Capodice JL, Lew DL,
Darke AK, et al. Effect of Acupuncture vs Sham Acupuncture or Waitlist Control on Joint Pain Related to Aromatase Inhibitors Among Women With Early-Stage Breast Cancer: A Randomized Clinical Trial. JAMA. 2018 Jul 10;320(2):167-176. [PubMed]

10. Lesi G, Razzini G, Musti MA, Stivanello E, Petrucci C, Benedetti B, et al. Acupuncture As an Integrative Approach for the Treatment of Hot Flashes in Women With Breast Cancer: A Prospective Multicenter Randomized Controlled Trial (AcCliMaT).J ClinOncol. 2016 May 20;34(15):1795-802. [PubMed]

11. Gramatikova M, Nikolova E, Mitova St. Nature, application and effect of kinesio-taping. Activities in Physical Education and Sport. 2014. pp.115-119

12. Evans R, Haas M, Schulz C, Leininger B, Hanson L, Bronfort G. Spinal manipulation and exercise for low back pain in adolescents: a randomized trial. Pain. 2018 Jul;159(7):1297-1307. [PubMed]

13. Nelson NL. Kinesio taping for chronic low back pain: A systematic 
review.J BodywMovTher. 2016 Jul;20(3):672-81. [PubMed]

14. Li Y, Yin Y, Jia G, Chen H, Yu $\mathrm{L}, \mathrm{Wu} \mathrm{D}$. Effects of kinesiotape on pain and disability in individuals with chronic low back pain: a systematic review and meta-analysis of randomized controlled trials. Clin Rehabil. 2019 Apr;33(4):596-606. [PubMed]

Please cite this article as: Mitova S, Gramatikova M, Avramova M, Stoyanov G. Kinesiotape methodology for chronic pain syndrome in the lumbosacral region. J of IMAB. 2021 Jul-Sep;27(3):3950-3954.

DOI: https://doi.org/10.5272/jimab.2021273.3950

Received: 02/02/2021; Published online: 21/09/2021

\section{Address for correspondence:}

Assis. Prof. Margarita Avramova, PhD

Department of Kinesitherapy, Faculty of Public Health, Healthcare and Sports, South-West University Neofit Rilski, Blagoevgrad,

66, Ivan Mihaylov Str., 2700 Blagoevgrad, Bulgaria.

E-mail: margo.arrials@gmail.com 